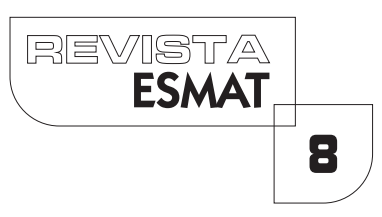

\title{
REEXAME OBRIGATÓRIO DAS SENTENÇAS PROFERIDAS CONTRA A FAZENDA PÚBLICA: OFENSA AO PRINCÍPIO DA PARIDADE DE ARMAS?
}

Glacielle Borges Torquato

Mestre em Prestação Jurisdicional e Direitos Humanos pela Universidade Federal do Tocantins (UFT). Graduada em Direito pela Universidade Federal do Tocantins (UFT), 2007. Pós-Graduanda em Teoria da Decisão Judicial pela Escola Superior da Magistratura Tocantinense (ESMAT). Pós-Graduada em Gestão do Judiciário pela FAEL, 20 I2. Pós-Graduada em Direito Municipal pela UNIDERP, 2009. Analista Judiciário do Tribunal de Justiça do Estado do Tocantins desde 2010 e chefe de Gabinete de Desembargador. E-mail: glacielletorquato@gmail.com

Spencer Vampré

Mestre em Prestação Jurisdicional e Direitos Humanos pela Universidade Federal do Tocantins (UFT). Graduado em Direito pela PUC - Campinas, 1998. Pós-Graduado em Direito Constitucional pela Unitins, 2008. Analista Judiciário do Tribunal de Justiça do Tocantins desde 2004 e assessor jurídico de Desembargador. Membro do Conselho Editorial da ESMAT.E-mail: spencervampre@yahoo.com.br

\section{Téssia Gomes Carneiro}

Mestre em Prestação Jurisdicional e Direitos Humanos pela Universidade Federal do Tocantins (UFT). Graduada pela UniParadversidade Salgado de Oliveira - Universo - Goiás, em 2004. Pós-Graduada em Direito Penal pela Universidade Federal de Goiás, em 2007. Defensora Pública no Tocantins desde janeiro de 2008.E-mail: tessiagomes@hotmail.com

\section{RESUMO}

O artigo $5^{\circ}$, caput, da Constituição Federal, de 1988, assim como o artigo I25, I, do Código de Processo Civil, sem descurar da natureza dos direitos envolvidos e postos sob julgamento, objetivam trazer uma reflexão sobre a efetiva ou suposta paridade de armas nos processos sujeitos ao duplo grau obrigatório, cuja controvérsia guarde relação com direitos fundamentais, analisado sob o prisma do direito de acesso à justiça e à razoável duração do processo. O presente trabalho, nessa perspectiva, visa aquilatar a suposta paridade havida na observância da norma expressa pelo artigo 475 do Código de Processo Civil, quando o direito colocado em julgamento tiver um viés de direito fundamental, cuja efetividade não pode sofrer o obstáculo imposto pelo tempo, decorrente da suspensão da eficácia da sentença. $\bigcirc$ resguardo do direito fundamental em análise deverá contar com a atividade criativa do magistrado, em conjunto com a participação das partes, num processo cooperativo. 
ESMAT GLACIELLE BORGES TORQUATO, SPENCER VAMPRÉ,TÉSSIA GOMES CARNEIRO

PALAVRAS-CHAVE: Paridade de armas. Reexame necessário. Direitos fundamentais. Cooperação.

\begin{abstract}
Our 1988's Federal Constitution (fifth article) and the Civil Procedure Code (article 125), without neglecting the nature of the rights involved and put on trial, aims to bring a reflection on the actual or perceived parity of weapons in processes subject to the mandatory double degree, whose controversial is related to fundamental rights, analyzed through the prism of the right of access to justice and the reasonable duration of the process. The present work, in this perspective, seeks to assess the alleged regarded parity in observance of the rule expressed in the article 475 of the Civil Procedure Code, where the right placed on trial have a fundamental right bias, whose effectiveness can not suffer the obstacle imposed by time, resulting from the suspension of the effectiveness of the judgment. The fundamental right protection must have the magistrate creativity, along the participation of the process subjects, in a cooperative process.
\end{abstract}

KEYWORDS: Arms parity. Mandatory review. Fundamental rights. Cooperation.

\title{
CONSIDERAÇÕES INICIAIS
}

A expressão "paridade de armas", no Direito Processual Civil, está umbilicalmente ligada à principiologia da igualdade, que, por sua vez, retoma a ideia de garantia dos direitos fundamentais, instrumento adequado à conformação dos direitos de envergadura constitucional.

Como efeito, a natureza do direito fundamental aquilatado neste estudo não é visto unicamente à luz da garantia do contraditório, como se poderia presumir. A questão vai além da análise puramente simplista, decorrência do princípio da igualdade, aqui compreendido sob o enfoque material.

É de se registrar que o conceito de igualdade difere no Estado Liberal, no Estado Social e no Estado Democrático de Direito. No primeiro, a igualdade aparece como contestação às mazelas presentes no regime absolutista, de modo que o seu ideal perpassa pela concepção de igualdade formal perante a lei, quando então a atividade do magistrado restringe-se a declarar a lei, sem interpretá-la. No segundo, com a concepção de igualdade material passa-se a permitir o tratamento desigual para os desiguais. Por fim, no atual Estado Democrático de Direito "ganha destaque a concepção material de igualdade, sem descuidar-se da igualdade formal, vindo ambas a balizar a conformação do 
REEXAME OBRIGATÓRIO DAS SENTENÇAS PROFERIDAS CONTRA A FAZENDA PÚBLICA: OFENSA AO PRINCÍPIO DA PARIDADE DE ARMAS?

processo civil." (SANTOS, 20 I I, p. 56). A igualdade material, portanto, pode ser compreendida, na lição do jurista, "no sentido de tratamento diferenciado de situações concretas dessemelhantes, tendo em vista evitar o aprofundamento das desigualdades realmente existentes na sociedade." (201 I, p. 55).

$\mathrm{Na}$ perspectiva processual, atribuindo vida ao artigo $5^{\circ}$, caput, da Constituição Federal, de 1988, assim como ao artigo 125, I, do Código de Processo Civil, dispositivo reproduzido no novo Código de Processo Civil, Lei $n^{\circ}$ | 3. I 05, sancionada em 16 de março de 2015 , sem descurar da natureza dos direitos envolvidos e postos sob julgamento, objetivar-se-á reflexão sobre a efetiva ou suposta paridade de armas nos processos sujeitos ao duplo grau obrigatório, nos quais a controvérsia guarde relação com direitos fundamentais, analisada sob o prisma do direito de acesso à justiça, razoável duração do processo e efetividade das decisões.

\section{DESENVOLVIMENTO}

\section{I O alcance da igualdade material no direito processual civil e o reexame necessário}

Conforme discorrido alhures, a igualdade descrita no artigo $5^{\circ}$, caput, da Constituição Federal, de 1988 (CF), visa oportunizar no processo o mesmo tratamento formal às partes. Também o Código de Processo Civil (CPC) trouxe previsão similar ao dispor sobre a necessidade de o magistrado dispensar igual tratamento àquelas, conforme se visualiza da redação do artigo | 25, inciso I'.

Art. 125. O juiz dirigirá o processo conforme as disposições deste Código, competindo-lhe:

I-assegurar às partes igualdade de tratamento; (CPC, art. I25, inc. I).

Contudo, é sabido que nem sempre os polos da demanda se encontram no mesmo patamar econômico ou social, de modo que a legislação infraconstitucional trouxe dispositivos que primam pela igualdade substancial, a exemplo da curadoria especial (CPC, artigo $9^{\circ}$ ), dos prazos em dobro (CPC, artigo | 88), da tramitação processual prioritária (Estatuto do idoso, Lei $n^{\circ}$ 10.74 I, de 2003, artigo 7I), da possibilidade de inversão do ônus da prova no direito consumerista (CDC, Lei n 8.078, de 1990), da assistência jurídica

Redação idêntica à do novo CPC, art. 139, I. 
gratuita (Lei de Assistência Judiciária n I.060, de 1950), dentre outros.

Nota-se que "O princípio da igualdade processual impõe a criação de uma série de regras processuais adequadas às particularidades de cada sujeito do processo." (DIDIER JR., 20 I2, p. 70). Desta feita, o legislador, ao desigualar os desiguais, proporcionará a paridade de armas necessária ao reequilíbrio entre as partes no curso do processo. Nesse sentido, ilustra a doutrina:

No processo civil legitimam-se normas e medidas destinadas a reequilibrar as partes e permitir que litiguem em paridade de armas, sempre que alguma causa ou circunstância exterior ao processo ponha uma delas em condições de superioridade ou inferioridade em face da outra. Mas é muito delicada essa tarefa de desequilíbrios privilegiados a pretexto de remover desigualdades (CINTRA, GRINOVER, DINAMARCO, 201 I, p. 60).

Além do legislador, também o juiz ao conduzir o processo, nos moldes da redação acima transcrita (CPC, artigo I 25, inciso I), deverá garantir igualdade de tratamento às partes, e com isso chegar a um resultado justo. Porém, se visualizadas as situações de desigualdades, poderá dispensar tratamento distinto entre aquelas, sem, todavia, afastar-se da imparcialidade.

Bueno (20 I I, p. 165), a respeito do assunto, esclarece que:

A isonomia ou igualdade deve ser entendida no sentido de que o Estado-juiz (o magistrado, que o representa) deve tratar de forma igualitária os litigantes. Seja dando-Ihes igualdade de condições de manifestação ao longo do processo, seja criando condições para que esta igualdade seja efetivamente exercitada.

Desta feita, tanto o legislador quanto o juiz deverão neutralizar as diferenças apresentadas. Para isso, a boa condução do processo pelo magistrado dependerá, dentre outros aspectos, de procedimento que permita adaptações, como na visão de Francisco Emilio Baleotti, segundo o qual, um procedimento rígido, sem espaço para a atuação judicial que vise adequar o processo, prima apenas pelo interesse privado e pela segurança jurídica, em detrimento do interesse público:

Esta forma procedimental - procedimento ordinário - rigidamente estruturado dentro da garantia do devido processo legal e caracterizado pelo contraditório prévio e seu esgotamento, pretendemos demonstrar ser fruto de uma ideologia que mais privilegia a segurança jurídica do que a justiça, ou seja: tem mais apreço pela atividade declaratória dos direitos postos em litígio do que pela sua efetiva proteção e efetivação e por isso encerra os poderes do juiz na condução do processo dentro de um figurino legal que o impede de alterar a rotina dos atos 
REEXAME OBRIGATÓRIO DAS SENTENÇAS PROFERIDAS CONTRA A FAZENDA PÚBLICA: OFENSAAO PRINCÍPIO DA PARIDADE DE ARMAS?

processuais, mesmo quando esta se mostre inadequada à natureza do direito posto em causa, uma vez que a própria norma processual infraconstitucional delimita a adequação dos procedimentos em abstrato. (BALEOTTI, 20।2, p. 392).

Não se deve perder de vista o papel desempenhado pelo direito processual civil, que nada mais é do que o instrumento para a efetivação do direito material. Dessa forma, eventual flexibilização das regras processuais, desde que amparada por fundamentação idônea, especialmente quando seu objetivo é contemplar o princípio da isonomia, deve ser objeto de reflexão pelos magistrados, ainda que altere a norma processual aplicável à hipótese concreta.

Segundo aponta Dinamarco, as desigualdades a serem observadas pelo legislador e pelo magistrado são diversas e de toda ordem, de modo que o tratamento diferenciado servirá para restabelecer a paridade rompida pelas circunstâncias sociais e econômicas, o que, por sua vez, requer preparo para alcançar a igualdade substancial. Continua o doutrinador afirmando que "Essas desigualdades que o juiz e o legislador do processo devem compensar com medidas adequadas são resultantes de fatores externos ao processo - fraquezas de toda ordem, como a pobreza, desinformação, carências culturais e psicossociais em geral" (DINAMARCO, 2009, p. 2 I3).

A isonomia avizinha-se da imparcialidade e do contraditório, pois a participação das partes no processo deverá ocorrer com paridade de armas, com o emprego de armas lícitas para o convencimento do magistrado.

Nesse sentido, Câmara (2009, p. 4 I ) leciona que:

o princípio da isonomia só estará sendo adequadamente respeitado no momento em que se garantir aos sujeitos do processo que estes ingressarão no mesmo em igualdade de armas, ou seja, em condições equilibradas. Este é o verdadeiro sentido da expressão par conditio, condições paritárias.

Recorde-se que tais armas deverão ser proporcionadas às partes por intermédio do procedimento previsto pelo legislador, o que, por sua vez, não impede que o juiz, no intuito de alcançar a igualdade substancial, conduza o feito com alteração da rotina processual, naquelas situações em que visualize desigualdades entre os polos. Entendimento contrário implicará enrijecer a atuação do magistrado, o qual desenvolverá apenas atividades declaratórias, sem produção criativa.

A respeito do assunto, esclarece Baleotti (20 I 2, p. 394) que:

O formalismo processual, corolário do princípio do devido processo legal, hoje 
não vigora com a força que se pretende, tampouco se pode pretender que a crença de que garantindo-se a forma apenas pela forma se atinja a melhor prestação jurisdicional não se sustenta (...) o apego exagerado ao princípio do devido processo legal, ao contrário de garantir uma boa ordem processual, atua exatamente no sentido oposto, impedindo o desenrolar do processo de modo a oferecer proteção adequada ao direito posto em causa.

A paridade de armas não significará equivalência absoluta de direitos e obrigações entre as partes, pois, justificada a diferença de tratamento, não haverá impedimento à distinção. Portanto, a igualdade material se mantém em perfeita sintonia com a paridade de armas no processo.

Com o aumento dos poderes do magistrado no processo, deverá ser proporcionado às partes um espaço maior de discussão para atender ao contraditório e, assim, evitar surpresas no julgamento. Com efeito, "tudo que o juiz decidir fora do debate já ensejado às partes corresponde a surpreendê-las, e a desconsiderar o caráter dialético do processo, mesmo que o objeto do decisório corresponda a matéria apreciável de ofício" (TEODORO JR e NUNES, 2009, p. 125). Essa orientação encontra-se em consonância com o dispositivo engendrado pelo Novo Código de Processo Civil, com entrada em vigor prevista para o dia 16 de março de 2016 , verbis:

Art. 10. $\bigcirc$ juiz não pode decidir, em grau algum de jurisdição, com base em fundamento a respeito do qual não se tenha dado às partes oportunidade de se manifestar, ainda que se trate de matéria sobre a qual deva decidir de ofício.

Trazendo as considerações suso transcritas às demandas que exigem o reexame necessário, poder-se-á questionar se a atividade criativa do juiz na garantia da igualdade substancial entre as partes processuais estaria garantida com a aplicação irrestrita na norma expressa pelo artigo 475 do atual Código de Processo Civil $^{2}$, que dispõe:

Art. 475. Está sujeita ao duplo grau de jurisdição, não produzindo efeito senão depois de confirmada pelo tribunal, a sentença:

I - proferida contra a União, o Estado, o Distrito Federal, o Município, e as respectivas autarquias e fundações de direito público;

II - que julgar procedentes, no todo ou em parte, os embargos à execução de dívida ativa da Fazenda Pública (art. 585, VI).

${ }^{2}$ Dispositivo reproduzido pelo novo CPC, no art. 496. 
REEXAME OBRIGATÓRIO DAS SENTENÇAS PROFERIDAS CONTRA A FAZENDA PÚBLICA: OFENSA AO PRINCÍPIO DA PARIDADE DE ARMAS?

A doutrina e jurisprudência pátrias sinalizam no sentido de que o mencionado dispositivo processual estaria atendendo à igualdade material, porquanto a Fazenda Pública guarda interesses da coletividade. De fato, até se poderia admitir a tese invocada e posta na legislação processual, desde que não impedisse a análise casuística pelo magistrado, notadamente nos casos em que o direito material invocado tem respaldo na Constituição Federal.

É imperioso registrar, nesse particular, que a análise do direito pelo julgador não deve se restringir à regra fria imposta na lei pelo legislador. Seu papel é muito mais gnosiológico e dinâmico do que puramente estático e declaratório. Como efeito, é seu dever, até mesmo para garantir a eficácia dos direitos improrrogáveis pelo decurso do tempo, sopesar, na análise do caso concreto, a necessidade, ou não, do referido reexame.

Outro não é o entendimento de Nery Júnior e Andrade Nery (2014, p. 885), ao lançarem comentários sobre o referido dispositivo legal:

O controvertido instituto, não poucas vezes (e não sem razão, pela aplicação que se lhe tem dado), acoimado de inconstitucional, vem sofrendo, por isso mesmo, mitigação legislativa (v.g., L I0352/0 I, LJEFed 13), deixando de incidir em numerosos casos, razão bastante para orientar o intérprete a restringir sua aplicação, quando isso mostrar-se razoável.

No estudo que ora se propõe, a flexibilização do instituto processual afigurase plenamente defensável, pois os interesses debatidos estão lastreados por direitos fundamentais, de forma que a justificativa para o afastamento da norma está na própria Constituição Federal. A interpretação do julgador deve estar abrangida por uma visão sistemática do ordenamento jurídico, a fim de salvaguardar os interesses tutelados.

\subsection{Contextualização histórica do reexame obrigatório}

Segundo CUNHA (20 I I), o instituto da revisão obrigatória das decisões judiciais tem origem no direito romano, previsto inicialmente com a finalidade de evitar erros, exageros, injustiças, desvios ou distorções, no tempo em que as funções jurisdicionais eram repartidas entre o poder e o povo.

Sua existência permaneceu na Idade Média, inclusive no Direito Português, no qual se impunha ao magistrado o dever de determinar o reexame de suas decisões, sob pena de sanções graves, dentre as quais a perda do cargo.

A figura subsistiu à Revolução Francesa, foi aperfeiçoada e passou a integrar a maioria dos ordenamentos jurídicos modernos. 
ESMAT GLACIELLE BORGES TORQUATO, SPENCER VAMPRÉ,TÉSSIA GOMES CARNEIRO

Considerado por alguns como elemento indispensável à democracia, foi previsto expressamente no Código de Processo Civil Brasileiro, de 1939. Atualmente integra o Capítulo VIII (Da Sentença e da Coisa Julgada) do Título VIII (Do Procedimento Ordinário) do Diploma de Ritos em vigor, nos seguintes termos:

\begin{abstract}
Art. 475. Está sujeita ao duplo grau de jurisdição, não produzindo efeito senão depois de confirmada pelo tribunal, a sentença: I - proferida contra a União, o Estado, o Distrito Federal, o Município, e as respectivas autarquias e fundações de direito público; II - que julgar procedentes, no todo ou em parte, os embargos à execução de dívida ativa da Fazenda Pública (art. 585, VI). § I o Nos casos previstos neste artigo, o juiz ordenará a remessa dos autos ao tribunal, haja ou não apelação; não o fazendo, deverá o presidente do tribunal avocá-los. § 20 Não se aplica o disposto neste artigo sempre que a condenação, ou o direito controvertido, for de valor certo não excedente a 60 (sessenta) salários mínimos, bem como no caso de procedência dos embargos do devedor na execução de dívida ativa do mesmo valor. § 30 Também não se aplica o disposto neste artigo quando a sentença estiver fundada em jurisprudência do plenário do Supremo Tribunal Federal ou em súmula deste Tribunal ou do tribunal superior competente.
\end{abstract}

Deve-se ressaltar que o instituto se localiza no capítulo atinente à coisa julgada, o que the confere a natureza de condição de eficácia da sentença, conforme assentou a jurisprudência do Superior Tribunal de Justiça:

\begin{abstract}
A remessa necessária, expressão do poder inquisitivo que ainda ecoa no ordenamento jurídico brasileiro, porque de recurso não se trata objetivamente, mas de condição de eficácia da sentença, como se dessume da Súmula 423 do STF e ficou claro a partir da alteração do art. 475 do CPC pela Lei 1 0.352/200 I, é instituto que visa a proteger o interesse público; dentro desse contexto, é possível alargar as hipóteses de seu conhecimento, atribuindo-lhe mais do que o efeito devolutivo em sua concepção clássica (delimitado pela impugnação do recorrente), mas também o chamado efeito translativo, quando se permite ao órgão judicial revisor pronunciar-se de ofício, independentemente de pedido ou requerimento da parte ou interessado, em determinadas situações, como, por exemplo, para dirimir questões de ordem pública." (REsp 959.338/SP, Rel. Ministro NAPOLEÃO NUNES MAIA FILHO, PRIMEIRA SEÇÃO, julgado em 29/02/20 I2, DJe 08/03/20 I2)
\end{abstract}

O Superior Tribunal de Justiça pontifica, ainda, que as situações em que o reexame não é enfrentado, seja na esfera penal, seja na civil, ensejam a cassação do acórdão e retorno do feito à instância precedente.

É de se notar que o instituto revela nítido intuito de proteção ao erário; caso 
REEXAME OBRIGATÓRIO DAS SENTENÇAS PROFERIDAS CONTRA A FAZENDA PÚBLICA: OFENSA AO PRINCÍPIO DA PARIDADE DE ARMAS?

contrário não haveria sentido em sua aplicação limitar-se às condenações superiores a sessenta salários mínimos, conforme mitigação editada pela Lei n 10.352, de 200 I , às hipóteses do reexame necessário.

Referida alteração legislativa surgiu em atendimento aos reclamos de efetividade à prestação jurisdicional, muito embora tenha selado a conclusão de que os interesses econômicos da Fazenda Pública constituem o mote norteador da ideia da paridade de armas no duplo grau obrigatório.

No enfoque estrito da regra processual, é induvidosa a obrigatoriedade do reexame para que a sentença proferida contra a fazenda pública tenha eficácia.

Sabe-se, porém, que a melhor interpretação do ordenamento jurídico se dá mediante análise de todo o sistema, sem olvidar as regras e princípios que o regem - sobretudo as que emanam da Constituição - às quais a validade do dispositivo processual está indubitavelmente condicionada. Trata-se do método hermenêutico denominado de interpretação lógico-sistemática, pelo qual os direitos e garantias fundamentais sempre estarão observados quando da ponderação do intérprete para aplicação de normas em aparente conflito.

Em caráter amplo, sobre a obrigatoriedade de reexame de decisões, vale lembrar, como bem observa GONÇALVES (2005, p. 35), que, dada a inexistência de disposição expressa na Constituição para que invariavelmente se efetive o duplo grau de jurisdição, diversas hipóteses em nosso ordenamento fazem com que ele não ocorra, ainda que provocado, sem que disso resulte inconstitucionalidade.

Nesse sentido, a exceção prevista no parágrafo terceiro do artigo 475 do Código de Processo Civil denota significativamente que a salvaguarda de direitos constitucionais, logicamente, se sobrepõe à suspensão de eficácia decorrente do reexame obrigatório, fundamentado exclusivamente na regra processual e motivado tão somente na proteção ao erário.

\subsection{Proteção a direitos fundamentais em confronto com a proteção ao erário}

Ante o aparente obstáculo à pronta aplicabilidade das sentenças condenatórias da fazenda em matéria que verse sobre Direitos Fundamentais, torna-se imperiosa a análise dos fundamentos que amparam os valores em confronto: proteção ao erário versus proteção aos direitos fundamentais. Como visto, a necessidade de reexame obrigatório das condenações da fazenda está assentada na proteção ao erário. Rege-se, portanto, por princípios gerais de interesse público, alguns deles mencionados por Paula (2009, pp. I04- 
ESMAT GLACIELLE BORGES TORQUATO, SPENCER VAMPRÉ,TÉSSIA GOMES CARNEIRO

105), como o da primazia do interesse público e da proporcionalidade dos meios aos fins, ambos diretamente atrelados ao Direito Público, além do princípio da indisponibilidade do interesse público, afeto ao Direito Administrativo.

De outro modo, vislumbram-se três frentes de princípios atinentes às questões dos direitos fundamentais: o direito de acesso à justiça, a razoável duração do processo e garantia dos direitos fundamentais.

Relativamente ao acesso à justiça, pertinente é a explanação de Paroski (2006, p. 225) no sentido de que o "acesso à justiça talvez seja o mais básico dos direitos fundamentais, pois que é através do seu exercício que outros direitos fundamentais podem ser assegurados quando violados, pela imposição de sua observância pelos órgãos estatais encarregados da jurisdição".

Seguindo a estrutura dos direitos fundamentais de Alexy, pode-se dizer que o direito de acesso à justiça (norma de direito fundamental consagrada na maioria das Constituições modernas) se enquadra na qualidade de princípio, como mandamento de otimização, podendo ser satisfeito em graus variados, nada impedindo que, na aplicação do caso concreto, ganhe contornos de regra para a hipótese vertente.

Especificamente em relação ao reexame necessário, o obstáculo observado quanto ao acesso à justiça cinge-se especificamente na impossibilidade de pleno cumprimento da sentença proferida em primeiro grau, antes da confirmação pelo Tribunal de Justiça, ainda que inexistente recurso voluntário.

A questão ganha preocupação maior quando a matéria afeta aos autos diz respeito à consagração de direitos fundamentais. Observe-se que o direito, conforme afirmado em linhas pretéritas, deve ser analisado de maneira sistêmica. Permitir que direitos fundamentais sejam alijados por uma norma de direito processual, e justificá-la no argumento da "paridade de armas" é inaceitável num Estado que deixou de ser liberal para atender à Democracia.

Insta salientar, por oportuno, o papel do julgador na garantia dos direitos fundamentais, o qual atua na qualidade de protagonista, sopesando a necessidade, ou não, do duplo grau obrigatório quando em pauta os direitos de natureza constitucional.

Em resposta ao aparente óbice processual à eficácia das sentenças protetivas dos direitos fundamentais (condenatórias da fazenda pública), conclui-se inequivocamente pela primazia da proteção aos direitos fundamentais, de envergadura constitucional, que merecem aplicação imediata, em detrimento de direitos pautados exclusivamente pelo critério econômico.

A razoável duração do processo, por sua vez, não pode ser tratada em dissonância com a ideia de cooperação, porquanto é dever não apenas do 
REEXAME OBRIGATÓRIO DAS SENTENÇAS PROFERIDAS CONTRA A FAZENDA PÚBLICA: OFENSA AO PRINCÍPIO DA PARIDADE DE ARMAS?

órgão jurisdicional, mas também dos litigantes, um comportamento destinado a garantir a celeridade, a lealdade processual e a boa-fé.

Daniel Mitidiero (2009, p. 102) fala com muita percuciência acerca do assunto:

\begin{abstract}
Por essa vereda, o contraditório acaba assumindo novamente um local destaque na construção do formalismo processual, sendo instrumento ótimo para a viabilização do diálogo e da cooperação no processo, que implica de seu turno necessariamente a previsão de deveres de conduta tanto para as partes quanto para o órgão jurisdicional (deveres de esclarecimento, consulta, prevenção e auxílio). O juiz tem o seu papel redimensionado, assumindo uma dupla posição: mostra-se paritário na condução do processo, no diálogo processual, sendo, contudo, assimétrico no quando da decisão da causa. A boa-fé a ser observada no processo, por todos os seus participantes (entre as partes, entre as partes e o juiz e entre o juiz e as partes), é a boa-fé objetiva, que se ajunta à subjetiva para a realização de um processo leal.
\end{abstract}

Esse é o espírito que deverá orientar o julgador na sua atuação criativa (não apenas declaratória), segundo a qual, na análise do caso concreto, poderá deixar de aplicar a suspensividade dos efeitos da sentença como regra geral, salvo quando dela resultar risco de lesão grave superior à que visou proteger, hipótese em que o juiz, ponderando os valores em questão, poderá excepcionalmente suspendê-la.

\title{
3 CONSIDERAÇÕES FINAIS
}

O duplo grau obrigatório, conquanto esteja respaldado na legislação processual civil, deve ser interpretado pelo magistrado à luz do caso concreto, sob o viés não apenas do acesso à justiça, mas também da razoável duração do processo e da garantia dos direitos fundamentais, tudo respaldado pela comparticipação das partes entre si, e destas com o julgador.

Nessa atividade criativa e dinâmica do magistrado, não se pode fugir da ponderação alexyana acerca dos valores colocados sob julgamento. Com efeito, o reexame necessário deve ser interpretado sistematicamente, considerando princípios de ordem constitucional, capazes de garantir o pleno exercício de direitos fundamentais pela eficácia da decisão prolatada pelo magistrado de piso. Entender de forma diversa seria prestigiar sobremaneira valores que, na tabela valorativa de Alexy, estariam em patamar inferior, não engessando, por assim dizer, a atividade judicial por meio do discrimem legislativo. 
A dinamicidade do direito, somada ao neoconstitucionalismo, que consagrou inúmeros direitos fundamentais, apontam para a exigência de processo cooperativo, tendo como mote norteador a justiça, a lealdade processual e principalmente a eficácia da prestação jurisdicional, que somente poderão ser atingidas com a flexibilização de normas que, sob o pretexto de garantirem suposta "paridade de armas", por vezes de cunho eminentemente econômico-financeiro, obstaculizam direitos de envergadura constitucional.

O magistrado, sob tal viés, deve estar atento ao seu papel criativo e à própria natureza das demandas que lhe são postas a julgamento, de maneira a garantir a prevalência dos direitos fundamentais, respaldado não apenas sob a natureza material do direito sob exame, mas também sob o aspecto processual de acesso à justiça e da razoável duração do processo, tendo em mente o dever cooperativo das partes litigantes para atingimento do desiderato.

\section{REFERÊNCIAS}

BALEOTTI, Francisco Emilio. Poderes do juiz na adaptação do procedimento. In: Revista de Processo. São Paulo, v. 37, n² 2 3, pp. 389-408, nov. 2012.

BRASIL, Constituição (1988). Constituição da República Federativa do Brasil: promulgada em 5 de outubro de 1988. Organização do texto: Yussef Said Cahali. I $4^{a}$ ed. rev., ampl. e atual. São Paulo: Editora Revista dos Tribunais, 2012. (RTMiniCódigos).

, Código de Processo Civil (1973). Código de Processo Civil: promulgado em II de janeiro de 1973. Organização do texto: Yussef Said Cahali. I $4^{a}$ ed. rev., ampl. e atual. São Paulo: Editora Revista dos Tribunais, 2012. (RTMiniCódigos).

BUENO, Cássio Scarpinella. Curso sistematizado de Direito Processual Civil. Teoria Geral de Direito Processual Civil I. $5^{a}$ ed. rev., atual. e ampl. São Paulo: Saraiva, 2011 .

CÂMARA, Alexandre Freitas. Lições de Direito Processual Civil. v. I. 19a ed. rev. Rio de Janeiro: Lumen Juris, 2009.

CINTRA, Antônio Carlos de Araújo; GRINOVER, Ada Pellegrini; DINAMARCO, Cândido Rangel. Teoria geral do processo. $27^{\mathrm{a}}$ ed. São Paulo: Malheiros, 2011 . 
DINAMARCO, Cândido Rangel. Instituições de direito processual civil. $6^{\mathrm{a}}$ ed. rev. e atual., São Paulo: Malheiros, 2009.

DIDIER JR., Fredie. Curso de direito processual civil. v. I, I $4^{\text {a }}$ ed. Salvador: Jus Podium, 2012.

MITIDIERO, Daniel. Colaboração no processo civil: pressupostos sociais, lógicos e éticos. São Paulo: Ed. RT, 2009.

NERY JÚNIOR, Nelson; ANDRADE NERY, Rosa Maria de. Código de Processo Civil comentado e legislação extravagante. I $4^{\mathrm{a}} \mathrm{ed}$. rev. ampl. atual. São Paulo: Editora Revista dos Tribunais, 2014.

PAROSKI, Mauro Vasni. Do direito fundamental de acesso à justiça. Scientia Juris, Londrina, v. I0, pp. 225-242, 2006.

SANTOS, Igor Raatz dos. Processo, igualdade e colaboração: os deveres de esclarecimento, prevenção, consulta e auxílio como meio de redução das desigualdades no processo civil. In: Revista de Processo. São Paulo, v. 36, n 192, pp. 47-80, fev. 2011 .

THEODORO JÚNIOR, Humberto; NUNES, Dierle José Coelho. Uma dimensão que urge reconhecer ao contraditório no direito brasileiro: sua aplicação como garantia de influência, de não surpresa e de aproveitamento da atividade processual. In: Revista de Processo. São Paulo, v. 34, n I 68, pp. I07|4|, fev. 2009. 


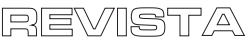

ESMAT GLACIELLE BORGES TORQUATO, SPENCER VAMPRÉ,TÉSSIA GOMES CARNEIRO 